\title{
BREAST MILK EFFECTS ON CLINICAL SIGNS OF ACUTE GASTROENTERITIS IN INFANTS UP TO 6 MONTHS OF AGE
}

\author{
DOI: https://doi.org/10.46733/PESH20145150pg \\ (Original scientific paper)
}

\author{
Marija Dimitrovska-Ivanova ${ }^{1}$, Elizabeta Zisovska ${ }^{2}$ \\ ${ }^{1}$ Department of Pediatrics, Clinical hospital, Shtip, North Macedonia \\ ${ }^{2}$ University Clinic for Gynecology and Obstetrics, Skopje, North Macedonia
}

\begin{abstract}
Acute gastroenteritis is one of the most common infections in childhood and it can be especially dangerous in the first 6 months of life with a higher risk of moderate and severe dehydration, especially in infants who are not exclusively breastfed. The aim of this study was to to evaluate the clinical pattern of acute gastroenteritis in infants up to 6 months of age, to correlate the severity of the disease related to the type of nutrition and to determine the possible microbiological causes of the acute gastroenteritis in this age group. A total of 23 infants with acute gastroenteritis divided into 2 groups based on the feeding patterns (type of milk) were included in the study. Investigated indicators were severity of symptoms, dehydration degree and the need for parenteral rehydration. It was identified a statistically significant association between group affiliation and severity of symptoms depending on the feeding type between first and second group. The most common cause of acute gastroenteritis in infants up to 6 months of age was Rotavirus. Our study has shown that exclusive breastfeeding reduces the risk of Rotavirus infection especially in the first 6 months of life OR=0.0758, 95\% CI (0.0071-0.8074). Breast milk has an effect on the severity of the clinical picture of acute gastroenteritis by reducing the number and severity of diarrheal episodes, the vomiting frequency, fever frequency and the risk of moderate and severe dehydration.
\end{abstract}

Key words: diarrhea, severity, breastfeeding, Rotavirus

\section{Introduction}

Acute gastroenteritis is one of the most common infection among children. Worldwide, about 1.7 billion cases of acute gastroenteritis occur in children under 5 years of age (Sdiri-Loulizi et al., 2008). In developed countries the course of acute infectious diarrhea is relatively mild, symptoms usually resolve spontaneously within few days. Unfortunately high mortality rate is still a heavyweight problem in countries with low economic development. Acute gastroenteritis can be particularly dangerous in the first 6 months of life with a higher risk of increased water and electrolyte loss with consequent moderate to severe dehydration especially in infants who are not exclusively breastfed. Acute gastroenteritis is defined as a decrease in stool consistency and/or an increase in the frequency of discharges ( $\geq 3$ in 24 hours) with or without fever and vomiting (Guarino et al., 2014). Acute diarrhea lasts between 7 and 14 days. Rotavirus is the most common cause of acute gastroenteritis, rarer causes are Adenovirus, Norovirus, and Astrovirus. Bacterial pathogens include Salmonella, Shigella, and less commonly Escherichia coli, Campylobacter jejuni, and Yersinia enterocolitica. Enterocyte infection leads to cell death, lumen extrusion, and atrophy of the intestinal villi, resulting in reduced intestinal surface area, with impaired digestive and absorption functions and acute transient malabsorptive diarrhea.

Breast milk is not only a source of energy, but also a very complex dynamic biological fluid that has a protective and immunomodulatory role (Filipovic, 1997). Breast milk is an optimal nutrition for infants and key factor in maintaining health and building the solid ground for growth and cognitive development. Although infants have antibodies vertically transmitted, they remain unprotected when they come in contact with new microorganisms. Breast milk can reduce this risk through the antibodies present in it and thus modify the infant's immune, metabolic and micro flora systems (Filipovic, 1997). Breast milk has antimicrobial activity against viruses, bacteria and protozoa, may reduce the incidence of gastrointestinal and non-intestinal infections in infants (Chirico et al., 2008). A number of studies have confirmed that 
breastfeeding has a protective role and reduces the risk of diarrhea, especially in infants up to 12 months of age (Diallo et al., 2019; Santos et al., 2015 \& Frank et al., 2015).

The aims of this study were:

- to evaluate the clinical pattern of acute gastroenteritis in infants up to 6 months of age

- to correlate the severity of the disease related to the type of nutrition.

- to determine the possible microbiological causes of the acute gastroenteritis in infants

\section{Material \& methods}

\section{Participants}

This was a prospective cohort study started in the period November 15, 2018 until December 31, 2019. The study included newborns and infants from birth to 6 months of age who were diagnosed with acute gastroenteritis. All infants were hospitalized at the Children's Department in Clinical Hospital - Shtip. Parents' written consent was obtained for each infant included in the study after extensive communication with them. An appropriate survey questionnaire was designed and responses were obtained from the infants' mothers. The questionnaire covered the following segments: infant age, nutrition (breast milk, milk formula or cow's milk) and weaning practice. Information on the onset of symptoms of acute gastroenteritis in the last 24 hours before admission, as well as information on the diet and health status of the nursing mother were included. Infants were divided in 2 groups according to age in months and according to milk nutrition and introduction of complementary food.

Group I included newborns and infants from birth to 6 months who were exclusively breastfed. Group II included newborns and infants from birth to 6 months of age who weren't exclusively breastfed and were on mixed milk nutrition. Exclusively breastfed were infants who were fed only with breast milk and didn't receive additional food or fluids (excluding oral rehydration solution, vitamins, minerals, and medications). The clinical picture and degree of dehydration were determined by physical examination and the degree of dehydration was graded as mild, moderate and severe through the use of a clinical scoring system. (World Health Organization: Integrated management of childhood illness-Module 4, Diarrhea). For each infant included in the study, a record sheet was filled and according to the severity of the clinical signs the need for parenteral rehydration was assessed during the hospital stay. The study didn't include infants whose diarrhea was due to a surgical or extra-intestinal cause, as well as infants who had received immunosuppressive therapy.

\section{Procedure}

From each infant included in the study, one sample of diaper stool was taken with a plastic spatula. This stool sample was collected in a sterile plastic cup with the general data of the patient and the code written on it and within 30 minutes was brought to the Microbiological Laboratory in the Center for Public Health (CPH) - Shtip. In this stool sample the presence of Rotavirus and Adenovirus with Immunochromatographic test (DUO ROTA-ADENOVIRUS - Check-1 VEDA.LAB, Alencon-France) was analyzed. From the same stool sample, a coproculture was performed which disproved the presence of enteropathogenic bacteria by sowing the stool sample on a suitable substrate.

\section{Statistical analysis}

The collected data were processed using the statistical program SPSS 20 and the following statistical methods:

Descriptive method: attributive statistical series were analyzed by determining percentages and numerical series with central tendency measures and with data dispersion measures. Statistical significance of the probability between the distributions of the frequencies of two attributive variables was estimated by the Difference test, and between the numerical series exploring the Student t-test. The Odds ratio-OR crosscorrelation is used to determine the relationship between the dependent-criterion variable and the independent. For CI (confidence interval 95\% CI) statistical significance was defined at the level of standard error less than $0.05(\mathrm{p})$. The results are shown in tables and figures.

\section{Results}

The analysis included 23 hospitalized infants from birth to 6 months of age with a diagnosis of acute gastroenteritis, divided in two groups. The first group included 7 (30.4\%) infants and the second group included $16(69.6 \%)$ infants, divided by age expressed in months and type of nutrition. 
Table 1 presents the infants with acute gastroenteritis by gender and age.

The average infant age in the first group was $2.1 \pm 0.9$ months, in the second group was $3.4 \pm 1.5$ months.

Table 1. Distribution of the infants according to the gender and age (I and II group)

\begin{tabular}{|c|c|c|c|c|}
\hline Group & \multicolumn{2}{|c|}{ I } & \multicolumn{2}{c|}{ II } \\
\hline Gender & Number & $\%$ & Number & $\%$ \\
\hline Male & 4 & 57.1 & 9 & 56.25 \\
\hline Female & 3 & 42.9 & 7 & 43.75 \\
\hline \multirow{2}{*}{$\begin{array}{c}\text { Age in } \\
\text { months }\end{array}$} & Number & Mean! SD & Number & Mean! SD \\
\cline { 2 - 5 } & 7 & $2.1 ! 0.899735$ & 16 & $3.4 ! 1.454877$ \\
\hline
\end{tabular}

SD: Standard deviation

The distribution of the clinical signs in both groups is presented in Table 2, which included the average number of vomiting, average number of liquid stools, fever, degree of dehydration, number of days of parenteral rehydration and length of hospital stay. The average number of vomiting 24 hours before admission in infants in the first group was $0.3 \pm 0.5$, in the second group was $4.6 \pm 3.3$, the difference was statistically significant $(\mathrm{p}=0.002669)$. The average number of liquid stools in infants 24 hours before admission in the first group was $3.7 \pm 0.8$, in the second group $10.4 \pm 4.9$, and the difference was statistically significant $(\mathrm{p}=0.002152)$. Fever was reported in $14.3 \%$ of infants in the first group and in $81.25 \%$ in the second group, with statistically significant percentage difference $(p=0.0025)$. All infants from the first group had mild degree of dehydration, in the second group a mild degree of dehydration was registered in $25.0 \%$, moderate in $43.75 \%$ and a severe degree of dehydration in $31.25 \%$ of infants. The average number of liquid stools during treatment in the first group was $9.0 \pm 2.2$, and in the second group was $21.2 \pm 8.5$, the difference between the average number of liquid stools was statistically significant $(p=0.001419)$. The average number of vomiting during treatment in the first group was $0.3 \pm 0.8$, and in the second group was $3.0 \pm 2.4$, the difference between the average number of vomiting was statistically significant ( $\mathrm{p}=0.008516)$. The average number of parenteral rehydration days in the first group was $0.7 \pm 0.8$, and in the second group it was $2.0 \pm 1.0$, the difference between the average number of parenteral rehydration days was statistically significant ( $p=0.005246)$. The average number of hospital days (length of stay) in the first group was $4.1 \pm 1.6$ and in the second group was $4.9 \pm 1.8$, the difference between the average number of hospital days was statistically insignificant for $\mathrm{p}>0.05(\mathrm{p}=0.318302)$.

Table 2. Clinical condition 24 hours before admission and during the hospitalization (I and II group)

\begin{tabular}{|l|c|c|c|c|c|c|c|c|}
\hline \multirow{2}{*}{$\begin{array}{l}\text { Group } \\
\text { Number of vomiting } \\
\text { 24 hours before } \\
\text { admission }\end{array}$} & $\begin{array}{c}\text { Averag } \\
\text { I }\end{array}$ & $\begin{array}{c}\text { Average } \\
\text { II }\end{array}$ & t-test & p & N I & N II & SD I & SD II \\
\cline { 2 - 8 } & $\begin{array}{c}0.28571 \\
4\end{array}$ & 4.56250 & -3.40460 & 0.002669 & 7 & 16 & 0.487950 & 3.265348 \\
\hline $\begin{array}{l}\text { Number of stools 24 } \\
\text { hours before } \\
\text { admission }\end{array}$ & 3.7 & 10.4 & -3.49610 & 0.002152 & 7 & 16 & 0.755929 & 4.951431 \\
\hline $\begin{array}{l}\text { Number of stools } \\
\text { during the } \\
\text { hospitalization }\end{array}$ & 9.0 & 21.2 & -3.67211 & 0.001419 & 7 & 16 & 2.236068 & 8.549610 \\
\hline $\begin{array}{l}\text { Number of vomiting } \\
\text { during the } \\
\text { hospitalization }\end{array}$ & 0.3 & 3.0 & -2.90250 & 0.008516 & 7 & 16 & 0.755929 & 2.394438 \\
\hline $\begin{array}{l}\text { Number of parenteral } \\
\text { rehydration days }\end{array}$ & 0.7 & 2.0 & -3.11436 & 0.005246 & 7 & 16 & 0.755929 & 0.966092 \\
\hline $\begin{array}{l}\text { Number of } \\
\text { hospitalization days }\end{array}$ & 4.1 & 4.9 & -1.02224 & 0.318302 & 7 & 16 & 1.573592 & 1.768945 \\
\hline \begin{tabular}{l} 
SD: Standard deviation; N: Number \\
\hline
\end{tabular}
\end{tabular}


Rotavirus was positive in 12 stool samples. In the first group Rotavirus was positive in one (14.3\%) infant and in the second group Rotavirus was positive in $11(68.75 \%)$ infants. In one infant from the second group Shigella flexneri was isolated and in one infant from the same group Adenovirus was isolated (Figure $1)$.

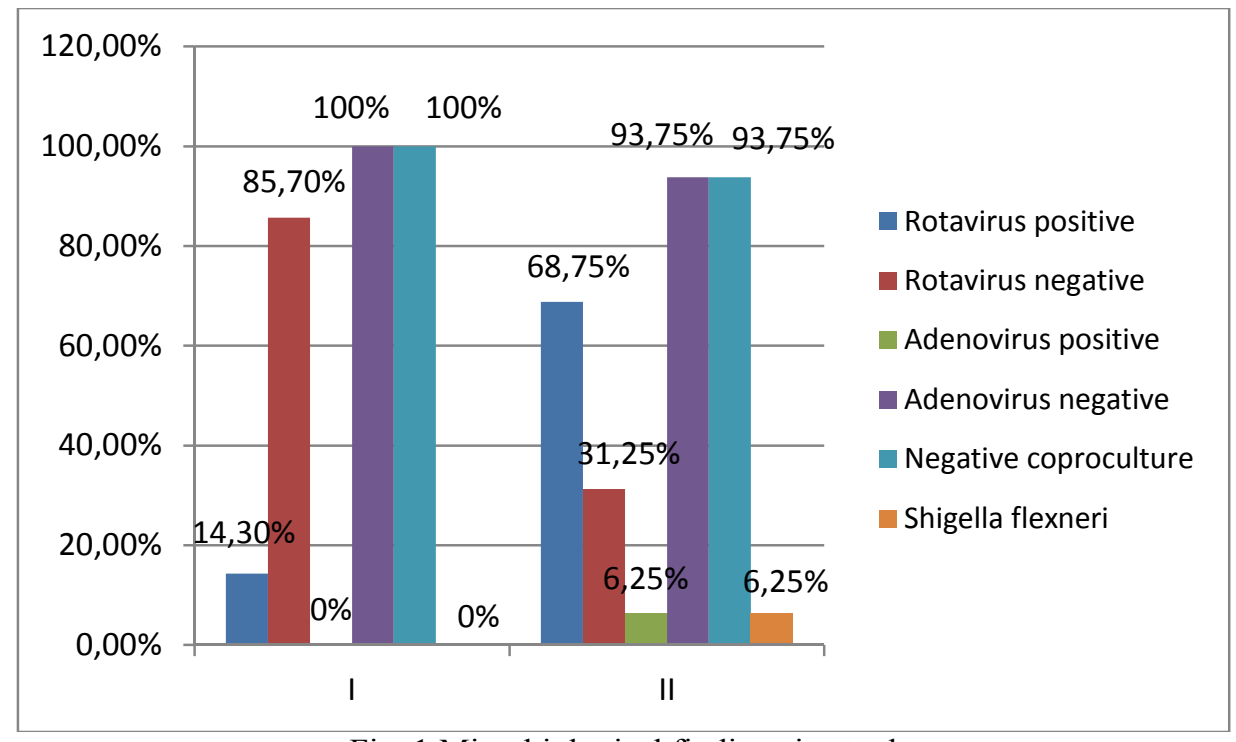

Fig. 1 Microbiological findings in stool

\section{Discussion}

Several studies have confirmed that breastfeeding has a protective role and reduces the risk of diarrhea, especially in infants up to 12 months of age. Dialo et al., 2019 noticed that breastfeeding discontinuation before the third month was found to be significantly associated with a high incidence of diarrhea at 6 months of age and between 6 and 12 months. Breastfeeding discontinuation (weaning) before the sixth month was also associated with a higher incidence of diarrhea at 6 months of age. Infants who were on milk formula for $\geq 3$ months had a higher incidence of diarrhea between 6 and 12 months. Frank et al., 2019 have shown that breastfeeding can play a protective role against respiratory and gastrointestinal acute illness in infants for at least the first 6 months of life by continuing to play the same role if breastfeeding continues after the sixth month of life. It has been observed that infants who are exclusively breastfed for up to 6 months and in which breastfeeding is continued for up to 12 months, have a lower rate of hospitalizations due to diarrhea, while in infants who have been fed with milk formula have had a higher incidence and rate of hospitalizations due to diarrhea. In the studies by Duffy et al., 1986 and Misra et al., 2007 was found that there was no difference in the incidence of Rotavirus diarrhea among exclusively breastfed and nonexclusively breastfed infants. Contrary to these claims, a study by Maranhão et al., 2008 found that diarrhea was more common in infants less than 6 months of age who were not breastfed or were on non-exclusive breastfeeding. Krawczyk et al., 2016 and Plenge-Bönig et al. 2010 have found that exclusive breastfeeding is effective in preventing Rotavirus infection by reducing the risk of Rotavirus infection in children, especially in the first 6 months of life. Some studies have shown that Rotavirus is a more common cause of acute gastroenteritis in infants than Adenovirus (Al-Ali et al., 2001 and Carraturo et al., 2008). These results support our findings that the most common cause of acute gastroenteritis in infants was Rotavirus. In this study, clinical signs and symptoms 24 hours before hospital admission were evaluated and clinical condition during treatment was assessed, as well as the need for parenteral rehydration, and the length of hospitalization. A statistically significant difference $(\mathrm{p}<0.05$.) for the average number of vomiting before admission was registered between the the two groups with less frequent vomiting in exclusively breastfed infants in the first group. Regarding the number of liquid stool 24 hours before admission, high statistically significant difference was registered between the first and second group. Sherif et al., 2015 did not prove statistical significance for the degree of dehydration between groups, but in our study all infants from the first group who were exclusively breastfeed had a mild degree of dehydration while in the second group only $25 \%$ of infants had a mild degree of dehydration, the rest had a moderate and severe degree of dehydration. Similar results were obtained in the study of Fuchs et al., 1996, which found that infants 
who were not breastfed were at higher risk of dehydration than those who were exclusively breastfed $(p=0.006)$. It has been proved that there is a statistically significant percentage difference for fever between the first and the second group. In the study of Weinberg et al., 1984 was shown that the vomiting frequency was significantly lower in breastfed infants. Similar results were obtained in this study, vomiting during treatment was less common in infants in the first group versus the second group. A study by Eaton-Evans and Dugdale, 1987 found that infants up to 6 months of age had a lower number of liquid stools and a lower vomiting frequency in those who were breastfed compared to other types of milk, indicating that breast milk has a protective effect on the intestines of infants younger than 6 months. In the present study regarding the average number of liquid stool during the treatment, there was a statistical significance for $\mathrm{p}<0.05$ between the first and second group. In our study, we observed statistical significance for the number of days of parenteral rehydration between the first and second group. For the number of hospital days, no statistical significance was proved either between the two groups. In contrast to our results in a study by Boccolini et al., 2012 it was shown that the increase in the prevalence of exclusive breastfeeding in infants younger than 4 months with acute diarrhea has a negative correlation with the duration of hospitalization $(\mathrm{Rho}=-0.483, \mathrm{p}=0.014)$. Our study has shown that exclusive breastfeeding is effective in preventing Rotavirus infection by reducing the risk of Rotavirus infection in children especially in the first 6 months of life $\mathrm{OR}=0.0758,95 \% \mathrm{CI}(0.0071-0.8074)$. This study had limitations because it was performed on a relatively small number of infants in a shorter follow-up period. During research of the published literature we revealed a small number of studies examining the direct effect of breast milk on the severity of the clinical signs in infants with acute gastroenteritis. For getting more significant evidence based conclusions, more studies such as this one, higher number of participants and follow up over a longer period of time are necessary.

\section{Conclusion}

This study has shown that breast milk has an effect on the severity of the clinical signs of acute gastroenteritis by reducing the vomiting frequency, the number and severity of diarrheal episodes, the risk for moderate and severe dehydration and fever frequency.

\section{References}

Al-Ali, R. M., Chehadeh, W., Hamze, M., Dabboussi, F., Sani, Hlais., \& Hassan, M. (2001). First description of gastroenteritis viruses in Lebanese children: a pilot study. Journal of Infection and Public Health, 4(2), 59-64.

Boccolini, C. S., Boccolini, P. M., de Carvalho, M. L., de Oliveira, M. I. (2012). Exclusive breastfeeding and diarrhea hospitalization patterns between 1999 and 2008 in Brazilian state capitals. Ciencia \& Saude Colectiva, 17(7), 1857-1863.

Carraturo, A., Catalani, V., \& Tega, L. (2008). Microbiological and epidemiological aspects of Rotavirus and enteric Adenovirus infections in hospitalized children in Italy. New Microbilogica, 31, 329-336.

Chirico, G., Marzollo, R., Cortinovis, S., Fonte, C., \& Gasparoni, A. (2008). Antiinfective Properties of Human Milk. Journal of nutrition, 138(9), 1801S-1806S

Diallo, A. F., McGlothen-Bell, K., Lucas, R., Walsh, S., Allen, C., Henderson, W. A., Cong, X., \& McGrath, J. (2019). Feeding modes, duration, and diarrhea in infancy: Continued evidence of the protective effects of breastfeeding. Public Health Nursing, $37(2), 155-160$.

Duffy, L. C., Byers, T. E., Riepenhoff-Talty, M., La Scolea, L. J., Zielezny, M., \& Ogra, P. L.(1986). The Effects of Infant Feeding on Rotavirus-Induced Gastroenteritis: A Prospective Study. American Journal of Public Health, 76(3), 259-63.

Eaton-Evans, J., Dugdale, A. E. (1987). Effects of feeding and social factors on diarrhea and vomiting in infants. Archives of Disease in Childhood, 62, 445-448.

Filipovic, D. (1997). Ishrana zdrave I bolesne dece: Humano mleko. Beograd: Nauka; pp. 75-97

Frank, N. M., Lynch, K. F., Uusitalo, U., Yang J, Lönnrot M., Virtanen, S. M., Hyöty, H., \& Norris, J. M. TEDDY Study Group. (2019). The relationship between breastfeeding and reported respiratory and gastrointestinal infection rates in young children. BMC Pediatrics, 19(1), 339.

Fuchs, S. C., Victora, C. G., Martines, J. (1996). Case-control Study of Risk of Dehydrating Diarrhoea in Infants in Vulnerable Period After Full Weaning. British Medical Journal, 313(7054), 391-394.

Guarino, A., Ashkenazi, S., Gendrel, D., Lo Vecchio, A., Shamir, R., \& Szajewska, H. (2014). Evidence-based guidelines for the management of acute gastroenteritis in children in Europe: update 2014. Journal of Pediatric Gastroenterology and Nutrition, 59(1), 132-152.

Krawczyk, A., Lewis, M. G., Venkatesh, B. T., \& Nair. S. N. (2016). Effect of Exclusive Breastfeeding on Rotavirus Infection among Children. Indian Journal of Pediatrics, 83(3), 220-225.

Maranhão, S. H., Medeiros, M. C. C., Scaletsky, I. C. A., Fagundes-Neto, U., \& Morais, M. B. (2008). The Epidemiological and Clinical Characteristics and Nutritional Development of Infants With Acute Diarrhoea, in North-Eastern Brazil. Annals of Tropical Medicine and Parasitology, 102(4), 357-365.

Misra, S., Sabui, K. T., Basu, S., \& Pal, N. (2007). A Prospective Study of Rotavirus Diarrhea in Children Under 1 Year of Age. Clinical Pediatrics, 46(8), 683-388 
Plenge-Bönig, A., Soto-Ramírez, N., Karmaus, W., Petersen, G., Davis, S., \& Forster J. (2010). Breastfeeding protects against acute gastroenteritis due to rotavirus in infants. European journal of Pediatrics, 169(12), 1471-1476.

Santos, F. S., Santos, F. C., Santos, L. H., Leite, A. M., \& Mello, D. F. (2015). Breastfeeding and protection against diarrhea: an integrative review of literature. Einstein, 13(3), 435-440.

Sdiri-Loulizi, K., Gharbi-Khélifi, H., de Rougemont, A., Chouchane, S., Sakly, N., Ambert-Balay, K., Hassine, M., Neji Guédiche, M., Aouni, M., \& Pothier, P. (2008). Acute infantile gastroenteritis associated with human enteric viruses in Tunisia. Journal of Clinical Microbiology, 46(4), 1349-1355.

Sherif, L. S., Abdel Raouf, R. K., El Sayede, R. M., El Wakkadd, A. S., Shoaib, A. R., Ali, H. M., El Refay, A. S. (2015). Glutathione Transferase as a Potential Marker for Gut Epithelial Injury versus the Protective Role of Breast Milk sIgA in Infants with Rota Virus Gastroenteritis. Open Access Macedonian Journal of Medical Sciences, 3(4), 676-680.

Weinberg, R. J., Tipton, G., Klish, W. J., Brown, M. R. (1984). Effect of Breast-Feeding on Morbidity in Rotavirus Gastroenteritis. Pediatrics, 74(2), 250-253. 